\title{
Short communication: Cow- and quarter-level milking indicators and their associations with clinical mastitis in an automatic milking system
}

\author{
J. F. Penry, ${ }^{* 1}$ P. M. Crump, ${ }^{*}$ P. L. Ruegg, ${ }^{*}$ and D. J. Reinemann† \\ *Department of Dairy Science, and \\ †Department of Biological Systems Engineering, University of Wisconsin-Madison, Madison 53706
}

\begin{abstract}
The aim of this study was to assess associations of cow-, udder-, and quarter-level factors with the risk of clinical mastitis $(\mathrm{CM})$ in cows managed using an automatic milking system. The primary hypothesis was that quarter peak milk flow rate (QPMF) is associated with increased risk of CM. A retrospective, case-control study was undertaken using data from a 1,549 cow farm using 20 automatic milking system units. All data from cows milked during March to December 2015 was available for analysis. Cases $(\mathrm{n}=82)$ were defined as cows diagnosed with their first case of CM between 24 and $300 \mathrm{~d}$ in milk in the current lactation. Healthy control cows $(n=6 /$ case $)$ were randomly matched based on identical parity, existence of milk records during the day in milk period corresponding to the 15 -d window before case diagnosis, average conductivity of $<5.5 \mathrm{mS} / \mathrm{cm}$ in that window, and no history of $\mathrm{CM}$ in the current lactation. Logistic regression was used to estimate effects of parity, quarter position, day in milk at diagnosis of CM, average of QPMF 15 d before CM diagnosis, udder milk yield, and milking interval on the probability of CM. Of the 6 predictor variables included in the model, only milking interval was significantly associated with the increased risk of quarter CM. We concluded that in a high-production, freestall-housed North American herd using automatic milking system, milking interval, but not QPMF, was associated with risk of CM.
\end{abstract}

Key words: clinical mastitis, milking interval, peak milk flow rate

\section{Short Communication}

For decades, researchers have evaluated associations between milk harvesting indicators and occurrence of clinical and subclinical mastitis. Early work by Dodd and Neave, (1951) found a strong, positive correlation

Received March 6, 2017.

Accepted August 3, 2017.

${ }^{1}$ Corresponding author: penry@wisc.edu between whole-udder milking rate $(\mathrm{kg} / \mathrm{min})$ and the incidence of mastitis in primiparous cows. This finding closely followed other research that reported large differences in whole-udder milk flow rates among cows, but relatively small variation over time within cow, regardless of stages of lactation or parity (Dodd and Foot, 1949). The relative stability over time, and within cow, of both whole-udder peak milk flow rate (UPMF) and quarter peak milk flow rate (QPMF) has since been supported by a study involving 38 cows (Tancin et al., 2006). An extensively referenced investigation, Grindal and Hillerton (1991) used an experimental challenge with Streptococcus agalactiae and Streptococcus dysgalactiae and reported a significant increase in new cases of clinical mastitis (CM) when QPMF was greater than $1.6 \mathrm{~kg} / \mathrm{min}$. Studies have also been conducted examining the association of UPMF and SCS. Data from 1,024 cows demonstrated no significant correlation between average UPMF and lactation average linear SCS (Halley et al., 2001); this supported a similar finding where UPMF was also found to have no association with linear SCS (Brown et al., 1986).

Milking interval (MI) and its association with mastitis has also been investigated, where MI is the elapsed time between consecutive milkings for an individual animal. Klungel et al. (2000) compared SCC level in automatic milking systems (AMS) with conventional milking of varying MI. Those authors reported no significant change in herd SCC level when AMS herds were compared with twice daily milking $(\mathbf{2} \times)$ or 3 times daily milking $(\mathbf{3} \times)$ conventional milking system herds or $2 \times$ were compared with $3 \times$ milking herds. This finding was supported in a similar study comparing SCC in milking systems of differing MI (Kruip et al., 2002). Research in a pasture-based, AMS herd determined that CM risk increased with longer MI (Hammer et al., 2012).

To date, few studies have been done on large-scale, freestall, AMS farms assessing associations of milk harvesting indicators with risk of CM. No published research has examined associations of QPMF with risk of $\mathrm{CM}$ due to naturally occurring infection in cows milked using AMS where per cow production exceeds 
$7,000 \mathrm{~kg} /$ lactation. The hypothesis of our observational study was that average QPMF, udder milk yield, or MI (quarter and cow milking indicators) were associated with increased risk of $\mathrm{CM}$ when milk was harvested using an AMS. Our primary aim was to assess associations of cow- and quarter-level milking indicators with risk of CM in cows milked using AMS.

This retrospective, case-control study was conducted using data from a 1,549 cow (total milking and dry cow number) commercial dairy farm located in the northeast United States that milk Holstein Friesian cows using 20 AMS units (DeLaval VMS, DeLaval, Tumba, Sweden). All primiparous milking cows were housed in 6 pens of 55 animals each, whereas multiparous milking cows were housed in 14 separate milking groups of the same capacity. All 20 pens were located within 1 rectangular barn. Dry cows were housed in a separate facility. Cows are housed year-round in freestalls that use new sand bedding over rubber mattresses. One freestall is available for each cow in each pen. The twice-daily partial mixed ration is supplemented with approximately $3 \mathrm{~kg} /$ cow per day of concentrate feed delivered in the AMS. As cows calve, they are allocated to individual pens so as to evenly distribute DIM among pens. Within each pen, cows are milked using a single AMS box and $<10 \%$ of animals were shifted among pens during the observation period. Cow flow between the freestall area, AMS, and feed-bunk in each pen is either a guided (18 pens) or semiguided (2 pens) traffic system with the basic configuration of walkways, freestall area, AMS premilking holding area, and feed-bunk similar for all 20 pens. Primiparous animals are granted milking permission if they have been absent from the AMS $>4 \mathrm{~h}$, whereas for multiparous animals permission is granted $>6$ h. No milk yield constraints were applied to milking permission.

Cow identification, milking start time (date, hour, minute, second), milking duration (minute, second; between cow entry into and exit from AMS box), quarter milk yield $(\mathrm{kg})$, quarter-average milk flow rate (AMF; $\mathrm{kg} / \mathrm{min})$, QPMF ( $\mathrm{kg} / \mathrm{min})$, quarter conductivity ( $\mathrm{mS} /$ $\mathrm{cm}$ ), and incomplete milkings were recorded for each cow milking from AMS units to a central database (Delpro, DeLaval). All milking records from March to December 2015 were collected $(845,026$ individual milking records), but data were only eligible for analysis if the following criteria were met: (1) if multiple lactations were recorded for a cow in 2015, only data from the most recent lactation was included; (2) each milking included complete data from all quarters; (3) whole-udder milk yield was 1 to $70 \mathrm{~kg} /$ milking, quarter milk yield was 0.1 to $15 \mathrm{~kg} /$ milking, and quarter AMF or QPMF was greater than $0.1 \mathrm{~kg} / \mathrm{min}$; and (4) MI was between 4 and $48 \mathrm{~h}$. After exclusion criteria were applied, 538,417 individual cow milking records were available for analysis. Incomplete milking in 1 or multiple quarters, for any record, removed $13.8 \%$ of the data, with most other records dropped based on multiple lactations in 2015.

Herd health records were used to identify all cows detected with CM within their enrolled lactation from March to December 2015. Clinical mastitis was detected using a standard protocol. Suspected cases were initially flagged in AMS software based on an absolute quarter milk conductivity of $>9 \mathrm{mS} / \mathrm{cm}$, deviation of quarter milk yield relative to a rolling average $(>30 \%)$, or MI greater than $24 \mathrm{~h}$. Confirmation of CM was based on visual observation of milk clots or milk discoloration or quarter inflammation by trained farm staff. Records included cow identification, date of diagnosis, and affected quarter. From this initial population of $155 \mathrm{CM}$ cows, only cows with an initial, single-quarter diagnosis of CM between 24 and 300 DIM were retained for analysis $(n=82)$. The lower limit was applied to allow for a sufficient time period before CM diagnosis to obtain approximately 20 to 50 milking records per cow and accounted for $61 \%$ of $73 \mathrm{CM}$ case exclusions. The upper limit was applied to balance the number of CM cases across a typical lactation length and accounted for $11 \%$ of exclusions. Remaining exclusions were due to incomplete calving date or CM records. This study was conducted under institutional animal care and use committee approved animal use protocol A005167.

All statistical analysis was performed using SAS 9.4 (SAS Institute, Cary, NC). Udder milk yield and milking was calculated by summing all quarter milk yields. Regression analysis was performed to determine if quarter milk yield was associated with QPMF and, hence, a potential confounder. For each cow, average QPMF and quarter milk yield were calculated per quarter and per 10-d DIM window for the period of 1 to 300 DIM. A linear regression was performed on the average QPMF per cow versus average quarter milk yield for DIM windows of 50 to 60,100 to 110,150 to 160, 200 to 210 , and 250 to 260 for all 4 quarters. The average regression slope coefficient and coefficient of determination value for all 20 linear regressions in the 5 separate 10-d DIM windows were calculated.

For all cases, a 15-d window from d 20 to 5 before the diagnosis date was identified. Within this 15-d window, the average udder milk yield, affected QPMF, and MI were calculated from all eligible milkings. For each case, 6 control cows were randomly selected from eligible cows. Six controls were selected to improve the precision of association measures (Dahoo et al., 2009). Eligibility criteria for controls were (1) equivalent parity; (2) milking records in the same DIM window; (3) average conductivity in the matching quarter of $<5.5 \mathrm{mS} / \mathrm{cm}$ 
during the selected 15-d window; and (4) no record of $\mathrm{CM}$ during the 2015 lactation period. The average udder milk yield, average QPMF of the corresponding control quarter, and average MI were calculated for each control within the 15-d window corresponding to the case. A 15-d window was chosen to allow for multiple milking observations to be aggregated without encroaching on the period where the effects of an established CM infection were likely. Hence, each case and her 6 controls contributed 1 average value each for udder milk yield, affected QPMF, and MI for analysis. The use of MI $>24 \mathrm{~h}$ for detection of CM in this herd has the potential to introduce bias into the analysis. However, examination of milking records in the $15 \mathrm{~d}$ window for $\mathrm{CM}$ or control cows in the study indicated no milkings recorded an MI $>24 \mathrm{~h}$ or an involuntary (fetched) milking. Removal of incomplete milkings from the study base ( $13.8 \%$ of data) may have increased MI for an individual animal on the day of record removal, but no trend favoring $\mathrm{CM}$ or control cows was determined. Hence, we concluded that bias has not been introduced through the data exclusion criteria applied. During preparation for the final analysis reported, a smaller data window of -5 to $-3 \mathrm{~d}$ was assessed, with this analysis yielding substantially the same results as for the wider time window. Given the wider analysis window incorporated a larger number of observations, this was chosen for presentation.

Data from all cases and controls were grouped according to affected (or equivalent control) quarter. Within this grouping, averages and standard error of the mean for udder milk yield, MI, DIM at CM diagnosis, QPMF (affected and healthy quarters), AMF (affected and healthy quarters), and parity were calculated. Cows were categorized as parity $\leq 2$ or $\geq 3$. Parity categorization were dichotomized in this way, as parity 3 and above have increased risk of CM. Previous analysis in the study herd (unreported) indicated primiparous cows have a small, but significantly reduced MI compared with multiparous cows, with this effect captured in analysis through MI in the logistic regression.

The SAS LOGISTIC procedure was used to estimate effect of quarter position, DIM, average QPMF, average udder milk yield, parity group, and MI on the probability of CM. The following model was used

$$
\begin{aligned}
\operatorname{Logit}(\pi)_{\mathrm{ijklmn}} & =\mu+\mathrm{Q}_{\mathrm{i}}+\mathrm{DIM}_{\mathrm{j}}+\mathrm{QPMF}_{\mathrm{k}}+\mathrm{UMY}_{1} \\
& +\mathrm{PG}_{\mathrm{m}}+\mathrm{MI}_{\mathrm{n}}+\varepsilon_{\mathrm{ijklmn}},
\end{aligned}
$$

where $\operatorname{Logit}(\pi)_{\mathrm{ijk} k \mathrm{mn}}=$ dependent variable: $\mathrm{CM}$ detected or $\mathrm{CM}$ not detected; $\mu=$ overall mean; $\mathrm{i}=1,2,3,4$ quarter (class, fixed effect); $j=j$ th DIM at diagnosis of CM (class, fixed effect); $\mathrm{k}=\mathrm{kth}$ value of predic- tor variable average QPMF (continuous, fixed effect); $l=1$ th value of predictor variable average udder milk yield (continuous, fixed effect); $\mathrm{m}=1,2$ parity group (class, fixed effect); $\mathrm{n}=\mathrm{nth}$ value of predictor variable MI (continuous, fixed effect); and $\varepsilon=$ residual error. Significance for calculated Wald tests on model coefficients were declared at the $P<0.05$ level. Each model coefficient represents the natural logarithm of the odds ratio and, using the standard error values, a $95 \%$ confidence interval was calculated for each odds ratio. This model was designed to assess the association of the described milking indicators with the risk of $\mathrm{CM}$, as outlined in the study aim; it was not intended to assess the usefulness of milking indicators, such as conductivity, as predictors of CM.

Cows in the study herd had 2.3 average lactations, average DIM of 133 , average daily milk yield of 34.6 $\mathrm{kg}$, and an average MI of $9.7 \mathrm{~h}$. During the study period, bulk milk SCC averaged 175,000 cells $/ \mathrm{mL}$. This herd is representative of freestall housed AMS herds in North America for stocking density, being within the commercial range reported for AMS (Hallen Sandgren and Emanuelson, 2017), although the large number of AMS units within a single barn is atypical. The average parity of cases and their matched controls was $>3.5$, which reflects the age structure of this herd. Due to an insufficient number of control animals in parity 7 , only animals up to parity 6 were included in the analysis.

The average values for the linear regressions representing five 10-d DIM windows, and all quarters, were 0.17 and 1.2 for the coefficient of determination and slope coefficient, respectively. The low coefficient of determination value indicates that $17 \%$ of variation in QPMF is explained by quarter milk yield data. By inference, it can be assumed that the same weak association exists between UPMF and udder milk yield. Other researchers have also reported nonsignificant or weak relationships between milk yield and UPMF (Halley et al., 2001; Weiss et al., 2004) or for both UPMF and QPMF (Tancin et al., 2006).

In a case-control study, eligibility criteria for control animals is designed to account for potential confounders, which are a common cause of both the risk factors and the disease outcomes. Quarter milk yield was not a potential confounder in our study and, because of this, quarter milk yield was not used as a matching criteria for cases and controls.

Quarter peak milk flow rate in case and control quarters ranged from 1.43 to $1.64 \mathrm{~kg} / \mathrm{min}$ (Table 1) and was greater than QPMF of $1.03 \mathrm{~kg} / \mathrm{min}$ reported by Ipema and Hogewerf (2008), who enrolled cows that had average daily milk yield of $32 \mathrm{~kg}$ that may be considered comparable to our study group. A high degree of correlation between udder (Rothenanger et al., 1995; Halley 
et al., 2001) and quarter (Weiss et al., 2004) AMF and peak milk flow rate (PMF) has been observed; thus, PMF provides a sound predictor of overall milking speed as indicated by AMF. Hogewerf and Ipema (2000) reported significant differences between front and rear QPMF in a study with 12 cows, but this was in contrast to no significant difference found between front and rear quarters by Tancin et al. (2003). Univariable analysis before modeling demonstrated a significant, but small, $3 \%$ increase in rear QPMF compared with front QPMF and a high degree of association between QPMF and quarter $\operatorname{AMF}\left(\mathrm{R}^{2}>0.85\right)$.

Of the 6 predictor variables included in the model, only MI was significant $(P=0.04)$. The odds ratio for MI was $1.06(95 \% \mathrm{CI}=1.00-1.13)$, indicating a $6 \%$ increase in the odds of CM with each hourly increase in MI. No other variables in the model output were close to significance.

The range in average MI for cows in our study was between 10.1 and $12.2 \mathrm{~h}$, which was longer than the MI of $8.3 \mathrm{~h}$ previously reported in an observational study involving 635 AMS herds (Tremblay et al., 2016). Analysis using the complete 1,549 cow data set measured an average MI of $8.4 \mathrm{~h}$ (20-300 DIM). We concluded that the difference between the average MI in the entire 1,549 herd and the case-control population $\mathrm{MI}$ is due to variation as a result of sampling, where not all DIM $(<24$ and $>300)$ are eligible for inclusion. Cases included in our study were between 105 and 174 DIM, which is in general agreement with data about CM in 50 large dairy herds (Oliveira et al., 2013). In our study, enrollment criteria precluded inclusion of cows with a diagnosis of CM before 24 DIM or after 300 DIM, making it difficult to infer the association identified in this analysis with cows diagnosed with CM between 1 and 23 and beyond 300 DIM.

We observed no association between risk of $\mathrm{CM}$ and average QPMF in the affected quarter. This result differs from previous results, although care needs to be exercised in comparing studies, as measurement of PMF (quarter vs. udder), presentation of mastitis (CM vs. subclinical mastitis), and stage of IMI (experimental challenge vs. naturally occurring) likely influence study outcomes. Using bacterial challenge with Streptococcus agalactiae $(\mathrm{n}=18$ cows $)$, researchers found increased QPMF associated with increased risk of CM (Grindal et al., 1991), where QPMF was categorized as either above or below $1.6 \mathrm{~kg} / \mathrm{min}$. Milking conditions used by Grindal et al. (1991) are not easily comparable with those found with AMS. In 2 experiments that also used experimental bacterial challenges, Lacy-Hulbert and Hillerton (1995) also found an association between increased QPMF and quarter CM infection in 18 cows exposed to Strep. agalactiae, but reported no associa-

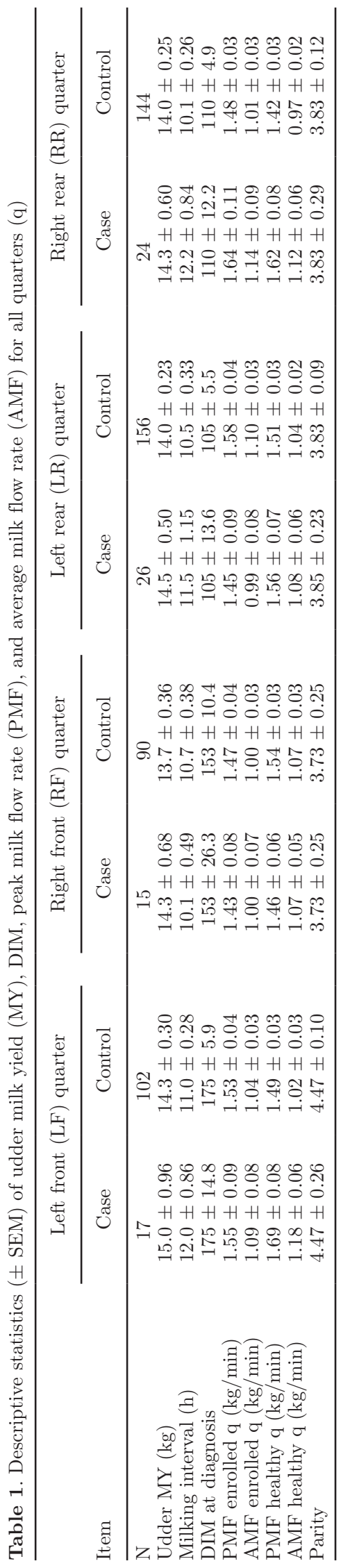


tion when 20 cows were exposed to Streptococcus uberis. Caution is required in extrapolating these results because of the highly contagious nature of Strep. agalactiae. An observational study with 108 cows identified a significant association between increased QPMF and the risk of quarter SCC greater than 50,000 cells $/ \mathrm{mL}$, but only for front quarters (Kohler and Kaufmann, 2003). Petermann et al. (2000) also reported an association between quarter SCC and increased QPMF, but without detail on the statistical test used. Hammer et al. (2012) performed a retrospective case-control study using data from a pasture-based AMS herd; based on univariate analysis, they reported an increased risk of CM associated with low average QPMF $(<1.0 \mathrm{~kg} / \mathrm{min})$ occurring 7 to $14 \mathrm{~d}$ before occurrence of CM. However, analysis of QPMF 0 to $7 \mathrm{~d}$ before $\mathrm{CM}$ indicated the risk of CM was associated with both low- and high-average QPMF $(>2.0 \mathrm{~kg} / \mathrm{min})$ with no mechanism proposed for this result. In a multivariate analysis, Hammer et al. (2012) reported an increased risk of CM associated only with high QPMF. One study, using 39 cows measured over $6 \mathrm{~d}$, observed no association between QPMF and the risk of quarter SCC greater than 50,000 cells/ $\mathrm{mL}$ (Tancin et al., 2003). In all the referenced studies examining the association of either high UPMF or QPMF with increased risk of CM, no authors proposed a causal pathway to disease as a result of high milk flow rate. Under constant milking system vacuum and pulsation, increased QPMF results from an increase in teat-end canal cross-sectional area (Upton et al., 2016). Underlying thinking behind a potential causal link may have been that, because the teat canal was wider during milk flow, bacterial entry was more probable under conditions where reverse flow milk droplets affected the teat end. Alternatively, a wider teat canal area may slow the refolding of the teat canal in the minutes postmilking, but this has not been demonstrated in any experiment. Regardless, we are left to speculate, as the potential mechanism is not articulated in the literature. The results of our study would appear to mitigate the potential for increased CM risk where increased milking speed (via increased QPMF) is an aim of any breeding program.

In our study we observed an increased risk of quarter CM with increasing MI. Milking interval has been associated with udder milk production rate $(\mathrm{kg} / \mathrm{h})$, so udder milk yield is not independent of MI (Wall and McFadden, 2012). Udder milk yield was not associated with CM risk in our findings. Unreported analysis in the study herd demonstrated a $2 \%$ increase in quarter milk production rate $(\mathrm{kg} / \mathrm{h})$ for each hour decrease in MI between 5 and $20 \mathrm{~h}$. However, because MI and milk production rate are inversely related, the effect on milk yield is moderated when MI is decreased. We proposed that this inverse relationship explains why MI has a significant association with the risk of CM in the study herd but udder milk yield does not. A review of milk quality changes observed when comparing $2 \times$ to $1 \times$ milking (increased MI) has shown an increase in udder SCC but not in CM (Stelwagen et al., 2013). Holmes et al. (1992) observed no differences in the prevalence of major mastitis-causing pathogens where $1 \times$ milking was compared with $2 \times$. Fogsgaard et al. (2015) examined MI changes in 2 AMS herds in the weeks around $\mathrm{CM}$ diagnosis and observed an increase in $\mathrm{MI}$ in the 4 wk before diagnosis was associated with CM only in multiparous cows. We assessed a similar DIM window before CM diagnosis, finding an association supportive of the Fogsgaard et al. (2015). Finally, our conclusion regarding MI is in agreement with Hammer et al. (2012), who also found an increased risk of CM with increasing MI for pastured cows milking using AMS. Although no experimental studies have confirmed these observational findings, we hypothesized that decreasing MI may decrease CM risk because of the more frequent cleaning of the exterior surface of teats, more frequent flushing of bacteria from the teat canal, and increased keratin turnover as a result of the pulsatile action of the milking liner in combination with shear forces produced by milk flow through the open teat canal.

This retrospective case-control study was designed to assess if increased QPMF was associated with an increased risk of quarter $\mathrm{CM}$ throughout the lactation on a farm using AMS. This association was not demonstrated; instead, we observed an association between increasing $\mathrm{MI}$ and $\mathrm{CM}$ risk. Our result regarding QPMF differs with the only other similar study, conducted on an AMS farm in a pasture-based system, and with results from previous small-scale experiments using highly contagious mastitis pathogen challenge protocols. We postulated that different farming systems with differing etiologies, housing, and milk production levels may account for differing associations with QPMF and CM risk.

\section{ACKNOWLEDGMENTS}

This research, conducted by the University of Wisconsin-Madison, is supported by Avon Dairy Solutions (Melksham, United Kingdom) and Dairy Australia (Melbourne). The researchers express their gratitude to the owners and staff at Mason Dixon Dairies (Gettysburg, PA) for their assistance with this experiment.

\section{REFERENCES}

Brown, C. A., S. J. Rischette, and L. H. Schultz. 1986. Relationship of milking rate to somatic-cell count. J. Dairy Sci. 69:850-854. 
Dahoo, I., W. Martin, and H. Stryhn. 2009. Veterinary Epidemiologic Research. 2nd ed. VER Inc., Charlottetown, PEI, Canada

Dodd, F. H., and A. S. Foot. 1949. Machine milking method. J. Brit. Dairy Farmers Assoc. 53:25-43.

Dodd, F. H., and F. K. Neave. 1951. 448. Machine milking rate and mastitis. J. Dairy Res. 18:240-245.

Fogsgaard, K. K., P. Lovendahl, T. W. Bennedsgaard, and S. Ostergaard. 2015. Changes in milk yield, lactate dehydrogenase, milking frequency, and interquarter yield ratio persist for up to 8 weeks after antibiotic treatment of mastitis. J. Dairy Sci. 98:7686-7698.

Grindal, R. J., and J. E. Hillerton. 1991. Influence of milk flow rate on new intramammary infection in dairy cows. J. Dairy Res. 58:263268.

Grindal, R. J., A. W. Walton, and J. E. Hillerton. 1991. Influence of milk flow-rate and streak canal length on new intramammary infection in dairy-cows. J. Dairy Res. 58:383-388.

Hallen Sandgren, C., and U. Emanuelson. 2017. Is there an ideal Automatic Milking System cow and is she different from an ideal parlor-milked cow? Pages 61-68 in 56th Natl. Mastitis Counc. Ann. Mtg. Proc., St. Pete Beach, FL. Natl. Mastitis Counc. Inc., New Prague, MN

Halley, B., J. Barlow, A. Bramley, J. Hillerton, D. Howell, and J. W Pankey. 2001. Observational studies on the association between peak milk flow rate and somatic cell count. Pages 179-180 in 40th Natl. Mastitis Counc. Ann. Mtg. Proc., Reno, NV. Natl. Mastitis Counc. Inc., Madison, WI

Hammer, J. F., J. M. Morton, and K. L. Kerrisk. 2012. Quarter-milking-, quarter-, udder- and lactation-level risk factors and indicators for clinical mastitis during lactation in pasture-fed dairy cows managed in an automatic milking system. Aust. Vet. J. 90:167-174.

Hogewerf, P. H., and A. H. Ipema. 2000. Analysis of differences in yield and milk flow properties between front and rear quarters. Pages 60-61 in Robotic Milking. Wageningen Academic Publishers, Wageningen, the Netherlands.

Holmes, C. W., G. F. Wilson, D. D. S. Mackenzie, and J. Purchas. 1992. The effects of milking once-daily throughout lactation on the performance of dairy cows grazing on pasture. Pages 13-16 in Proc. N. Z. Soc. Anim. Prod. Vol. 52. New Zealand Society of Animal Production, Cambridge, New Zealand.

Ipema, A. H., and P. H. Hogewerf. 2008. Quarter-controlled milking in dairy cows. Comput. Electron. Agric. 62:59-66.

Klungel, G. H., B. A. Slaghuis, and H. Hogeveen. 2000. The effect of the introduction of automatic milking systems on milk quality. J. Dairy Sci. 83:1998-2003.
Kohler, S. D., and O. Kaufmann. 2003. Quarter-related measurements of milking and milk parameters in an AMS-herd. Milchwissenschaft 58:3-6.

Kruip, T. A. M., H. Morice, M. Robert, and W. Ouweltjes. 2002. Robotic milking and its effect on fertility and cell counts. J. Dairy Sci. 85:2576-2581.

Lacy-Hulbert, S. J., and J. E. Hillerton. 1995. Physical characteristics of the bovine teat canal and their influence on susceptibility to streptococcal infection. J. Dairy Res. 62:395-404.

Oliveira, L., C. Hulland, and P. L. Ruegg. 2013. Characterization of clinical mastitis occurring in cows on 50 large dairy herds in Wisconsin. J. Dairy Sci. 96:7538-7549.

Petermann, M., W. Wolter, C. Kotting, B. Kloppert, H. Seufert, and M. Zschock. 2000. Single quarter milk flow profiles and rate of subclinical mastitis in automatic milking systems. Pages 120-121 in Robotic Milking. Wageningen Academic Publishers, Wageningen, the Netherlands.

Rothenanger, E., R. M. Bruckmaier, and J. W. Blum. 1995. Association and dissociation of single quarter and total milk flow in dairy-cows - Effects of milking with and without pre-stimulation. Milchwissenschaft 50:63-67.

Stelwagen, K., C. V. C. Phyn, S. R. Davis, J. Guinard-Flament, D. Pomies, J. R. Roche, and J. K. Kay. 2013. Reduced milking frequency: Milk production and management implications. J. Dairy Sci. 96:3401-3413.

Tancin, V., A. H. Ipema, D. Peskovicova, P. H. Hogewerf, and J. Macuhova. 2003. Quarter milk flow patterns in dairy cows: Factors involved and repeatability. Vet. Med. (Praha) 48:275-282.

Tancin, V., B. Ipema, P. Hogewerf, and J. Macuhova. 2006. Sources of variation in milk flow characteristics at udder and quarter levels. J. Dairy Sci. 89:978-988.

Tremblay, M., J. P. Hess, B. M. Christenson, K. K. McIntyre, B. Smink, A. J. van der Kamp, L. G. de Jong, and D. Dopfer. 2016. Factors associated with increased milk production for automatic milking systems. J. Dairy Sci. 99:3824-3837.

Upton, J., J. F. Penry, M. D. Rasmussen, P. D. Thompson, and D. J. Reinemann. 2016. Effect of pulsation rest phase duration on teat end congestion. J. Dairy Sci. 99:3958-3965.

Wall, E. H., and T. B. McFadden. 2012. Triennial lactation symposium: A local affair: How the mammary gland adapts to changes in milking frequency. J. Anim. Sci. 90:1695-1707.

Weiss, D., M. Weinfurtner, and R. M. Bruckmaier. 2004. Teat anatomy and its relationship with quarter and udder milk flow characteristics in dairy cows. J. Dairy Sci. 87:3280-3289. 